\title{
Concurrent pathways to explain solvent and substituent effects for solvolyses of benzoyl chlorides in ethanol-trifluoroethanol mixtures
}

\author{
T. William Bentley*a and In Sun Koo ${ }^{\mathrm{b}}$ \\ ${ }^{a}$ Chemistry Unit, Grove Building, College of Medicine, Swansea University, \\ Swansea SA2 8PP, Wales, UK \\ ${ }^{b}$ Department of Chemistry Education and Research Institute of Natural Science, \\ Gyeonsang National University, Jinju, 660-701, Korea \\ E-mail: t.w.bentley@swansea.ac.uk
}

\section{Dedicated to Professor Keith Smith on the occasion of his 65th anniversary}

\begin{abstract}
Rate constants are reported at $25^{\circ} \mathrm{C}$ for solvolyses of $p$-Z-substituted benzoyl chlorides $\left(\mathrm{Z}=\mathrm{O}_{2} \mathrm{~N}\right.$, $\mathrm{Cl}, \mathrm{H}, \mathrm{Me}$, and $\mathrm{MeO}$ ) in 2,2,2-trifluoroethanol (TFE) in binary mixtures with water or ethanol. Product selectivities $\left(k_{\mathrm{TFE}} / k_{\text {water }}\right)$ are also reported. Previous work in which rate constants for solvolyses of benzoyl chlorides are correlated with $\sigma$ constants is re-evaluated. V-shaped plots (assuming concurrent reactions) are constructed from logarithms of rate constants $v s . \sigma$ (not $\sigma^{\bullet}$ ) for substituent effects or a suitable parameter for solvent effects. Conditions are established for which it is predicted that concurrent mechanisms (one dissociative, one associative) each contribute $50 \%$ towards the observed rate constants.
\end{abstract}

Keywords: Acid chlorides, solvolysis, kinetics, substituent effects, solvent effects

\section{Introduction}

Differences in reaction mechanisms are usually discussed as if they occur abruptly from one to another due to changes in rate-limiting step, ${ }^{1}$ or due to changes enforced by the lifetimes of intermediates. $^{2}$ Solvolyses of electron-rich benzoyl halides (e.g. $\mathbf{1}, \mathrm{Z}=\mathrm{MeO}$ or $\mathbf{2}^{3 \mathrm{a}}$ ) occur via a dissociative/ionization processes, whereas electron-deficient substrates (e.g. 1, $\mathrm{Z}=\mathrm{O}_{2} \mathrm{~N}$ ) occur via addition/associative processes. ${ }^{1 \mathrm{~b}, 3 \mathrm{~b}, 3 \mathrm{c}}$ We now investigate conditions under which both of these two processes could occur concurrently.<smiles>[X]c1ccc(C(=O)Cl)cc1</smiles>

$\mathbf{1}, \mathrm{Z}=\mathrm{O}_{2} \mathrm{~N}, \mathrm{Cl}, \mathrm{H}, \mathrm{Me}, \mathrm{MeO}$

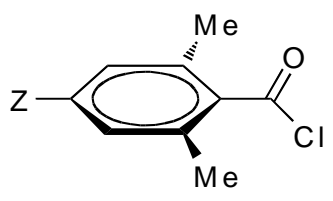

2 
A change in mechanism from one to another is often inferred from a change in slope for a plot of $\log k$ (rate constant) $v s$. a suitable parameter when substituents or solvents are varied. ${ }^{4}$ Recent DFT calculations indicate that the rate enhancing effects of both electron-donating and electronwithdrawing substituents on solvolyses of acid chlorides (1) in water can be explained by a concerted $\mathrm{S}_{\mathrm{N}} 2$ mechanism along with large changes in transition state structure. ${ }^{5}$ The purpose of our study is to provide further experimental evidence for the alternative mechanistic explanation ${ }^{6,7}$ of simultaneous (concurrent) reaction pathways.

Solvent effects in binary trifluoroethanol (TFE) mixtures will be correlated with those for $\mathbf{1}, \mathrm{Z}=$ $\mathrm{MeO}$ to allow for the effects of solvent ionising power and of aromatic ring solvation. ${ }^{7}$ It has recently been found that substituent effects for dissociative solvolyses of benzoyl chlorides correlate unexpectedly well with the original Hammett $\sigma$ function. ${ }^{8}$ The two types of correlation (for substituents and solvents) will provide the first independent estimates of the locations where each of the two pathways contributes $50 \%$ to the observed rate constant.

\section{Results and Discussion}

Kinetic data are summarized in Table 1 for TFE-water and in Table 2 for ethanol-TFE. The reliability of some previously published data ${ }^{9}$ has been questioned ${ }^{3 \mathrm{~b}}$ (see also Table 1 , footnotes c and $\mathrm{d}$, and Table 2 , footnote $\mathrm{d}$ ), and data from this source ${ }^{9}$ have been excluded.

Table 1. Rate constants $\left(10^{4} \mathrm{k} / \mathrm{s}^{-1}\right)$ for solvolyses of $p$-Z-substituted benzoyl chlorides (1) in trifluoroethanol-water mixtures at $25^{\circ} \mathrm{C}^{\mathrm{a}}$

\begin{tabular}{cccccc}
\hline Solvent: \% w/w & \multicolumn{5}{c}{ Substituent $(\mathrm{Z})$} \\
\cline { 2 - 6 } $\mathrm{CF}_{3} \mathrm{CH}_{2} \mathrm{OH}$ & $\mathrm{O}_{2} \mathrm{~N}$ & $\mathrm{Cl}$ & $\mathrm{H}$ & $\mathrm{Me}$ & $\mathrm{MeO}^{\mathrm{b}}$ \\
\hline 100 & $0.0064^{\mathrm{c}}$ & 3.0 & 19.6 & 204 & $3.49 \times 10^{3 \mathrm{~d}}$ \\
$97^{\mathrm{e}}$ & 0.099 & 4.46 & 36.3 & 349 & $5.66 \times 10^{3}$ \\
$70^{\mathrm{e}}$ & $11.2^{\mathrm{b}}$ & 28.5 & 195 & $1.41 \times 10^{3}$ & $1.8 \times 10^{4}$ \\
$50^{\mathrm{b}}$ & 43.7 & 73.2 & $544^{\mathrm{f}}$ & $3.05 \times 10^{3}$ & $5.1 \times 10^{4 \mathrm{~g}}$ \\
$30^{\mathrm{b}}$ & 178 & 403 & $2.63 \times 10^{3}$ & $1.41 \times 10^{4}$ & $1.64 \times 10^{5 \mathrm{~h}}$ \\
Water $^{\mathrm{i}}$ & 805 & $1.9 \times 10^{3}$ & $1.14 \times 10^{4 \mathrm{j}}$ & $6.5 \times 10^{4}$ & $5.2 \times 10^{5 \mathrm{k}}$ \\
\hline
\end{tabular}

${ }^{a}$ Determined conductimetrically in duplicate except where stated otherwise; typical errors are $\pm 3 \%$.

${ }^{\mathrm{b}}$ This work. ${ }^{\mathrm{c}}$ Reference $3 \mathrm{~b}$; also 54.2 , possibly due to arithmetic error in reference 9; our data at other temperatures: $0.13\left(50.0^{\circ} \mathrm{C}\right), 1.56\left(75.0^{\circ} \mathrm{C}\right) ; \Delta \mathrm{H}^{\neq}=22.7 \mathrm{kcal} \mathrm{mol}^{-1}, \Delta \mathrm{S}^{\neq}=-10.7 \mathrm{cal} \mathrm{mol}^{-1} \mathrm{~K}^{-1}$. d Reference 9 reports a significantly higher value of 5010. ${ }^{\mathrm{e}}$ Data from reference $10 \mathrm{a}$. ${ }^{\mathrm{f}}$ Data from reference $10 \mathrm{~b} .{ }^{\mathrm{g}}$ Calculated from the following data: $\left(10^{2} k,{ }^{\circ} \mathrm{C}\right): 9.80,-5.0 ; 40.2,5.0$; $\Delta \mathrm{H}^{\neq}=20.4 \mathrm{kcal} \mathrm{mol}^{-1}, \Delta \mathrm{S}^{\neq}=13.1 \mathrm{cal} \mathrm{mol}^{-1} \mathrm{~K}^{-1}$. ${ }^{\mathrm{h}}$ Calculated from the following data: $\left(10^{2} k,{ }^{\circ} \mathrm{C}\right)$ : 69.3, -4.9; 213, 5.0; $\Delta \mathrm{H}^{\neq}=16.3 \mathrm{kcal} \mathrm{mol}^{-1}, \Delta \mathrm{S}^{\neq}=1.6 \mathrm{cal} \mathrm{mol}^{-1} \mathrm{~K}^{-1}$. ${ }^{\mathrm{i}}$ Average of two measurements (references 11a and 11b) by stopped flow spectrophotometry; the solvent also contained $3.85 \%$ acetonitrile. ${ }^{\mathrm{j}}$ Other values are $1.1 \times 10^{4}$ (reference $1 \mathrm{~b}$ ) and $1.5 \times 10^{4}$ (reference $10 \mathrm{~b}$ ). ${ }^{\mathrm{k}}$ Average of 5.8. and 4.6. 
Table 2. Rate constants $\left(10^{4} \mathrm{k} / \mathrm{s}^{-1}\right)$ for solvolyses of $p$-Z-substituted benzoyl chlorides $(\mathbf{1})$ in ethanoltrifluoroethanol mixtures at $25^{\circ} \mathrm{C}^{\text {a }}$

\begin{tabular}{cccccc}
\hline Solvent: $\%$ & \multicolumn{5}{c}{ Substituent $(\mathrm{Z})$} \\
\cline { 2 - 6 } v/v EtOH & $\mathrm{O}_{2} \mathrm{~N}$ & $\mathrm{Cl}$ & $\mathrm{H}$ & $\mathrm{Me}$ & $\mathrm{MeO}^{\mathrm{b}}$ \\
\hline $100^{\mathrm{c}}$ & $135^{\mathrm{d}}$ & 12.1 & 7.48 & 5.24 & $9.86^{\mathrm{e}}$ \\
$80^{\mathrm{c}}$ & 66.9 & 9.51 & 7.20 & 7.00 & 32.5 \\
$70^{\mathrm{c}}$ & 49.6 & 7.98 & 6.43 & 8.35 & 43.6 \\
$60^{\mathrm{c}}$ & 33.4 & 5.74 & 6.05 & 11.2 & 84 \\
$50^{\mathrm{c}}$ & 19.4 & 3.95 & 5.74 & 15.4 & 140 \\
$40^{\mathrm{b}}$ & 10.0 & 2.80 & 5.45 & 20.9 & 275 \\
$20^{\mathrm{b}}$ & 1.79 & 1.84 & 9.12 & 64.4 & 940 \\
$10^{\mathrm{b}}$ & 0.47 & 1.87 & $13.0^{\mathrm{f}}$ & 97.2 & 1560 \\
$5^{\mathrm{b}}$ & $0.055^{\mathrm{g}}$ & 2.32 & $17.6^{\mathrm{h}}$ & 180 & 2970 \\
\hline
\end{tabular}

${ }^{a}$ Determined conductimetrically in duplicate except where stated otherwise; typical errors are $\pm 3 \%$. ${ }^{\mathrm{b}}$ This work. ${ }^{\mathrm{c}}$ Data from reference 12 , except stated otherwise. ${ }^{\mathrm{d}}$ Reference 9 reports a significantly higher value of $215 .{ }^{\mathrm{e}}$ Reference $13 .{ }^{\mathrm{f}} \mathrm{Data}$ at other temperatures: $2.63\left(10.0{ }^{\circ} \mathrm{C}\right), 56.5\left(40.0{ }^{\circ} \mathrm{C}\right)$; $\Delta \mathrm{H}^{\neq}=18.0 \mathrm{kcal} \mathrm{mol}^{-1}, \Delta \mathrm{S}^{\neq}=-11.3 \mathrm{cal} \mathrm{mol}^{-1} \mathrm{deg}^{-1} .{ }^{\mathrm{g}}$ Calculated from data at other temperatures: $0.75\left(50.0^{\circ} \mathrm{C}\right), 7.1\left(75.0^{\circ} \mathrm{C}\right) ; \Delta \mathrm{H}^{\neq}=19.4 \mathrm{kcal} \mathrm{mol}^{-1} \Delta \mathrm{S}^{\neq}=-11.4 \mathrm{cal} \mathrm{mol}^{-1} \mathrm{~K}^{-1}$.

${ }^{\mathrm{h}}$ Other data: $3.47\left(10.0^{\circ} \mathrm{C}\right), 72.2\left(40.0^{\circ} \mathrm{C}\right) ; \Delta \mathrm{H}^{\neq}=17.8 \mathrm{kcal} \mathrm{mol}^{-1}, \Delta \mathrm{S}^{\neq}=-11.4 \mathrm{cal} \mathrm{mol}^{-1} \mathrm{~K}^{-1}$.

Solvent effects can be explained quantitatively using the extended Grunwald-Winstein equation (1), in which logarithms of rate constants $(\log k)$ relative to rate constants in $80 \% \mathrm{v} / \mathrm{v}$ ethanol-water $\left(\log k_{0}\right)$ are correlated with solvent ionizing power $\left(Y_{\mathrm{Cl}}\right.$, based on solvolyses of 1-adamantyl chloride) and solvent nucleophilicity $\left(N_{\mathrm{T}}\right)$; values of substrate responses $l$ and $m$ are then obtained by fitting data for each substrate to equation (1) and $c$ is a residual term. ${ }^{3 \mathrm{~b}}$

$$
\log \left(k / k_{0}\right)=l N_{\mathrm{T}}+m Y_{\mathrm{Cl}}+c
$$

Solvolyses of $\mathbf{1}, \mathrm{Z}=\mathrm{MeO}$ in 37 solvents respond mainly to changes in solvent ionizing power and fit equation (1) with $l=0.31$ and $m=0.81,{ }^{3 \mathrm{~b}}$ consistent with a dissociative reaction mechanism. In contrast, solvolyses of $1, Z=\mathrm{O}_{2} \mathrm{~N}$ in 34 solvents respond mainly to changes in solvent nucleophilicity and fit equation (1) with $l=1.78$ and $m=0.54,{ }^{3 b}$ consistent with an associative mechanism. Solvolyses of $1, \mathrm{Z}=\mathrm{Me}$ gave $l=0.41$ and $m=0.73$, also consistent with a dissociative mechanism, but two equations were required for each substrate to fit the responses of other substrates $(\mathbf{1}, \mathrm{H}$ and $\mathrm{Cl})$, indicating concurrent reaction pathways. ${ }^{3 \mathrm{~b}}$

How reliable are conclusions based on equation (1)? Multi-parameter correlations should be applied cautiously, ${ }^{14}$ and it is known that aromatic ring solvation effects are not accounted for explicitly; this can achieved using Kevill's solvent parameter, $(I),{ }^{15,16}$ but an alternative is to chose a different similarity model for $Y$. Liu et al. ${ }^{17,18}$ based a $Y_{\mathrm{BnCl}}$ scale on solvolyses of 2-aryl-2adamantyl chloride, data for which is limited by inadequate solubility in less aqueous media. As an 
alternative, we chose solvolyses of $\mathbf{1}, \mathrm{Z}=\mathrm{MeO}$ as a similarity model for solvolyses of acid chlorides. ${ }^{6,7}$ Comparisons of solvolyses of $\mathbf{1}, \mathrm{Z}=\mathrm{MeO}$ with $Y_{\mathrm{BnCl}}$ indicate that rates of solvolyses of $\mathbf{1}, \mathrm{Z}=\mathrm{MeO}$ are enhanced by weak nucleophilic solvent assistance, ${ }^{9}$ consistent with $l=0.31$ (equation 1). ${ }^{3 \mathrm{~b}}$

In addition to refining the correlations of solvent effects, additional and independent support for concurrent pathways will be obtained from substituent effects. Recent research has provided new insights into the selection of appropriate substituent constants (e.g. the original Hammett $\sigma$ or an alternative for cations $\sigma^{+}$). There is a measurable resonance effect in some $\sigma$ constants, ${ }^{19,20}$ and there is also a large effect of electron-donating substituents on the $\mathrm{C}-\mathrm{Cl}$ bond length and on the negative charge at the chlorine atom in benzoyl chlorides $(\mathbf{1}) .^{21}$ The stabilisation energies, calculated from equation (2), ${ }^{21}$ were recently shown to correlate with $\sigma,{ }^{8}$ so the resonance demand incorporated into Hammett's $\sigma$ constants may be sufficient to account for substituent effects on cationic reactions of benzoyl chlorides. In contrast, 2,6-dimethylbenzoyl chlorides (2) require the enhanced resonance demand of $\sigma$ constants, ${ }^{3 a}$ probably because the unconjugated perpendicular conformation of the chloride (2) leads to a greater change in conjugation energy in the acylium transition state. ${ }^{8}$
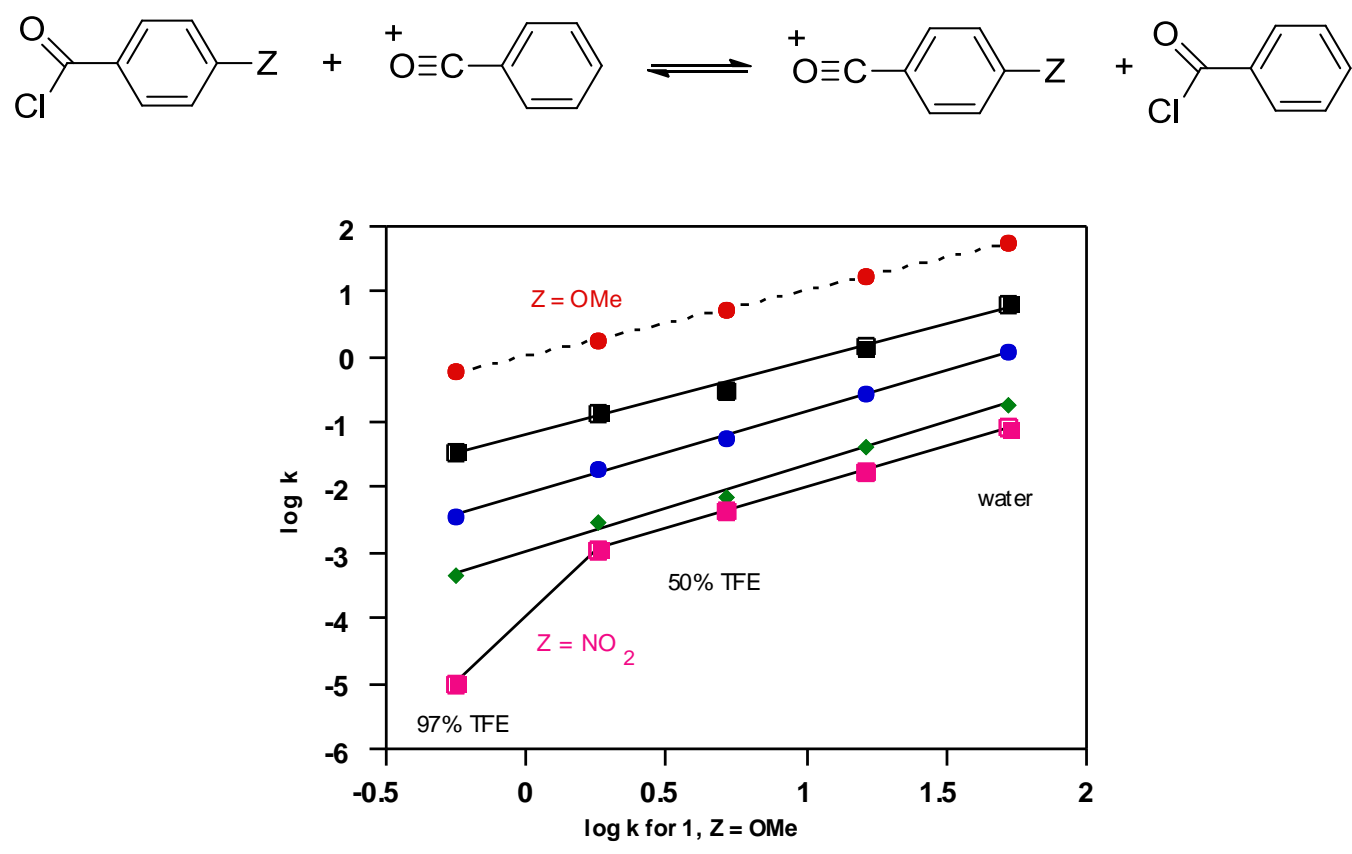

Figure 1. Logarithms of rate constants for solvolyses of acid chlorides (1) in trifluoroethanol-water vs. data for $(\mathbf{1}, \mathrm{Z}=\mathrm{MeO})$; data from Table 1 .

Correlations of $\log k$ for TFE/water mixtures (Figure 1) show remarkably similar solvent effects; slopes (Figure 1) increase in the order 1.0 for $1, Z=\mathrm{MeO}$ (by definition), $1.14 \pm 0.06$ ( $\mathrm{Z}=$ $\mathrm{Me}), 1.25 \pm 0.03(\mathrm{Z}=\mathrm{H}), 1.27 \pm 0.01\left(\mathrm{Z}=\mathrm{O}_{2} \mathrm{~N}\right) \sim 1.31 \pm 0.05(\mathrm{Z}=\mathrm{Cl})$. Since solvolyses of $\mathbf{1}, \mathrm{Z}=$ $\mathrm{MeO}$ and $1, Z=\mathrm{O}_{2} \mathrm{~N}$ are thought to solvolyse by different mechanisms, ${ }^{1 b, 3 b, 3 c, 6}$ the linearity of Figure 1 is in part fortuitous due to the limited range of solvents, and the data point for $1, Z=\mathrm{O}_{2} \mathrm{~N}$ in $97 \%$ TFE deviates from the correlations. 


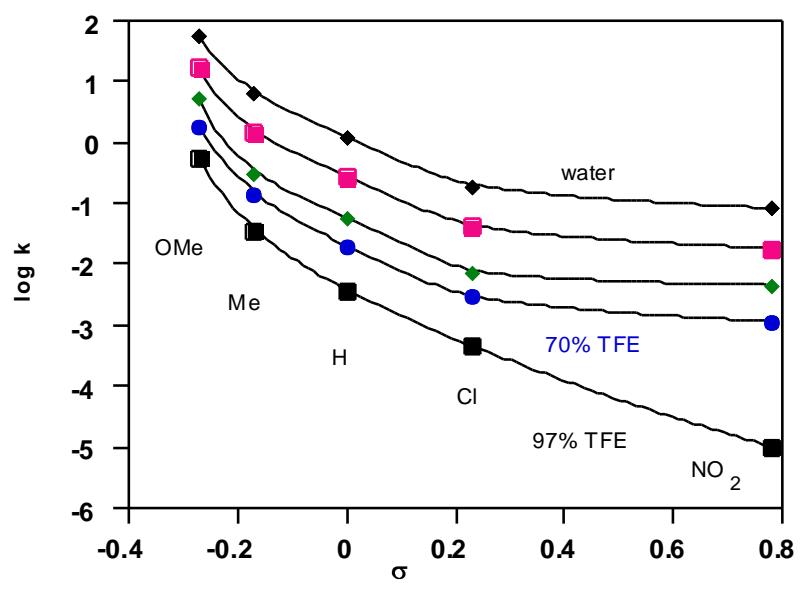

Figure 2. Logarithms of rate constants for solvolyses of acid chlorides (1) in trifluoroethanol-water $v s$. Hammett $\sigma$; data from Table 1 .

Addition of $3 \%$ water to TFE causes small rate increases (Table 1 ) for solvolyses of $1, \mathrm{Z}=$ $\mathrm{MeO}, \mathrm{Me}, \mathrm{H}$ and $\mathrm{Cl}$ ). Our kinetic data confirm that there is a large rate decrease on changing from $97 \%$ to $100 \%$ TFE for $1, Z=\mathrm{O}_{2} \mathrm{~N}^{3 \mathrm{~b}}$ consistent with a mechanistic change. The $\sigma$ plot for $100 \%$ TFE is linear (Figure 4), and this may be due to a switch to the dissociative pathway, even for $\mathbf{1}, \mathrm{Z}=$ $\mathrm{O}_{2} \mathrm{~N}$ for which $\Delta \mathrm{S}^{\neq}=-10.7 \mathrm{cal} \mathrm{mol}^{-1} \mathrm{~K}^{-1}$ (Table 1 , footnote $\mathrm{c}$,); in contrast, solvolyses of $\mathbf{1}, \mathrm{Z}=\mathrm{O}_{2} \mathrm{~N}$ in $97 \%$ TFE-water have a more highly negative $\Delta \mathrm{S}^{\neq}$of $-30.4 \mathrm{cal} \mathrm{mol}{ }^{-1} \mathrm{~K}^{-1} \cdot{ }^{10 a}$ As the associative pathway is highly sensitive to changes in solvent nucleophilicity, ${ }^{3 \mathrm{~b}}$ and the nucleophilicity of $97 \%$ TFE is greater than $100 \% \mathrm{TFE}^{23}$ a relatively abrupt change from associative in $97 \%$ TFE to dissociative pathways in $100 \%$ TFE is plausible. From a linear $\sigma^{+}$plot, we proposed previously ${ }^{10 a}$ that solvolyses of $1, Z=\mathrm{O}_{2} \mathrm{~N}$ in $97 \%$ TFE-water were dissociative, but a highly negative $\Delta \mathrm{S}^{\mp}$ was unexplained, and $\sigma$-plots are now preferred. ${ }^{8}$

The products of reaction with TFE-water are a carboxylic acid (3), and a TFE ester (4). Product selectivities ( $S$, equation 3, Table 3) vary significantly with solvent composition for solvolyses of $\mathbf{1}$, $\mathrm{Z}=\mathrm{O}_{2} \mathrm{~N}$, but not for the other substrates. Absolute values of $S$ for solvolyses of $\mathbf{1}, \mathrm{Z}=\mathrm{MeO}, \mathrm{Me}, \mathrm{H}$ and $\mathrm{Cl}$ vary from substrate to substrate, as observed for 4 -substituted benzyl chlorides, ${ }^{22}$ and consistent with solvolyses within the $S_{N} 2-S_{N} 1$ mechanistic spectrum.

$$
\mathrm{S}=[\mathrm{TFE} \text { ester product }] /[\text { acid product }] \times[\text { water }] /[\mathrm{TFE}]
$$

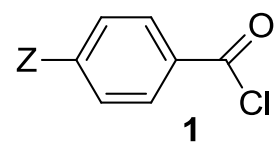

$\stackrel{\mathrm{CF}_{3} \mathrm{CH}_{2} \mathrm{OH} / \mathrm{H}_{2} \mathrm{O}}{\longrightarrow}$

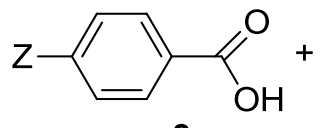

3

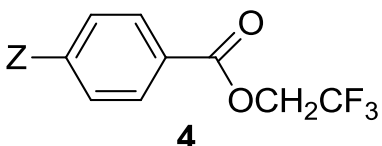

4 
Table 3. Product selectivities ( $S$, Equation 3) for solvolyses of $p$-Z-substituted benzoyl chlorides (1) in trifluoroethanol-water mixtures at $25^{\circ} \mathrm{C}^{\text {a }}$

\begin{tabular}{cccccc}
\hline Solvent: \% w/w & \multicolumn{5}{c}{ Substituent $(\mathrm{Z})$} \\
\cline { 2 - 6 } $\mathrm{CF}_{3} \mathrm{CH}_{2} \mathrm{OH}$-water & $\mathrm{O}_{2} \mathrm{~N}$ & $\mathrm{Cl}$ & $\mathrm{H}$ & $\mathrm{Me}$ & $\mathrm{MeO}^{\mathrm{b}}$ \\
\hline 97 & 0.057 & 0.48 & $0.25^{\mathrm{b}}$ & 0.45 & 0.21 \\
70 & 0.089 & 0.47 & $0.23^{\mathrm{c}}$ & 0.40 & 0.21 \\
50 & 0.16 & 0.47 & $0.23^{\mathrm{c}}$ & 0.41 & 0.22 \\
30 & 0.20 & 0.41 & 0.20 & 0.35 & 0.22 \\
\hline
\end{tabular}

${ }^{a}$ Determined by reverse phase HPLC analyses at least in duplicate. ${ }^{\mathrm{b}}$ Reference $1 \mathrm{~b}: \mathrm{S}=0.34$ for $90 \% \mathrm{v} / \mathrm{v}$ solvent $(92.5 \% \mathrm{w} / \mathrm{w})$; our earlier value of 0.1 (reference $10 \mathrm{~b}$ ) appears to be too low. ${ }^{\mathrm{c}}$ In satisfactory agreement with the published value of 0.2 (reference $10 \mathrm{~b}$ ).

Most of the $\sigma$ plots for TFE-water mixtures (Figure 2) are strongly curved, consistent with mechanistic changes by transition state variation ${ }^{5}$ (but not excluding competing pathways). There is much stronger evidence for mechanistic changes in the plots for ethanol-TFE (Figures 3 and 4), because the $\log k$ plots for both solvents and substituents show clear minima.
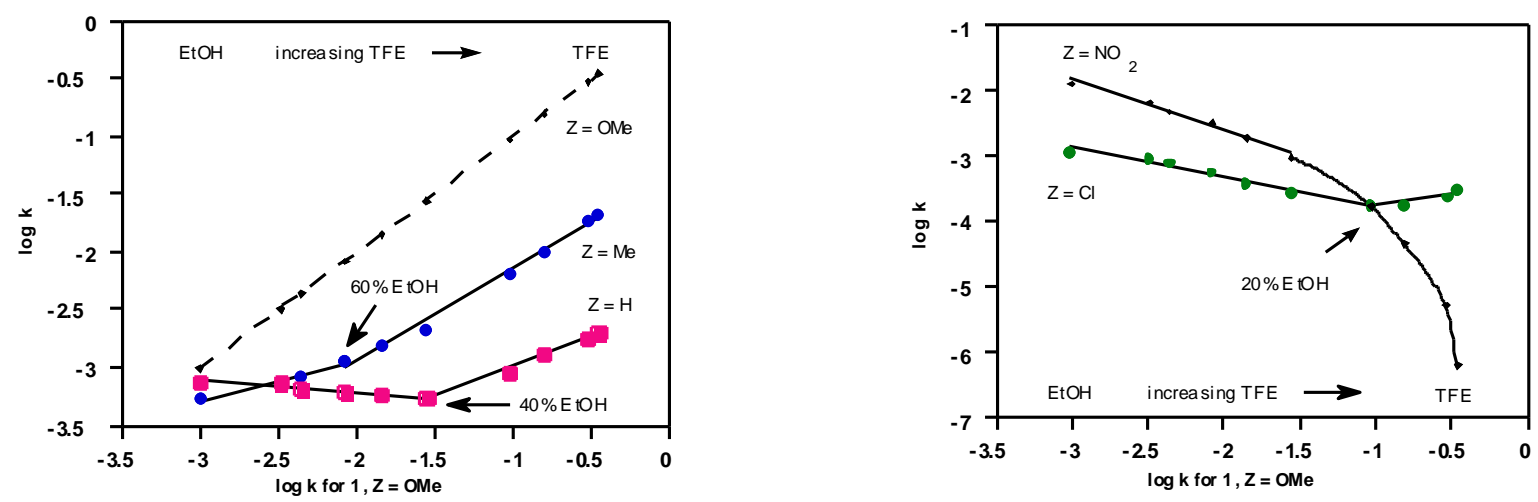

Figure 3. Logarithms of rate constants for solvolyses of acid chlorides, left $(\mathbf{1}, \mathrm{Z}=\mathrm{MeO}, \mathrm{Me}, \mathrm{H})$ and right $\left(1, \mathrm{Z}=\mathrm{Cl}\right.$ and $\left.\mathrm{O}_{2} \mathrm{~N}\right)$, in ethanol-trifluoroethanol $v s$. data for $(\mathbf{1}, \mathrm{Z}=\mathrm{MeO})$; the data are directly from Table 2 , so are uncorrected for competing reaction pathways; two plots are shown to minimise crowding around $\log k=-3$.

The slope of the solvent effect plot (Figure 3, left) is +1.0 for $\mathbf{1}, \mathrm{Z}=\mathrm{MeO}$ (by definition) and solvolyses of $\mathbf{1}, \mathrm{Z}=\mathrm{Me}$ give a good linear correlation from 100\% TFE to $60 \%$ ethanol/TFE (slope: $0.80 \pm 0.03, r=0.996, n=7$ ); the data for $80 \%$ ethanol/TFE and 100\% ethanol are above an extrapolated correlation line (not shown), consistent with a mechanistic change between 60 and $80 \%$ ethanol/TFE for solvolyses of $1, Z=M e$; the $\sigma$-plots for 60 and $80 \%$ ethanol/TFE (Figure 4, right) have minima around $\sigma=-0.1$ (approximately corresponding to $\mathrm{Z}=\mathrm{Me}$ ), so provides independent support. 

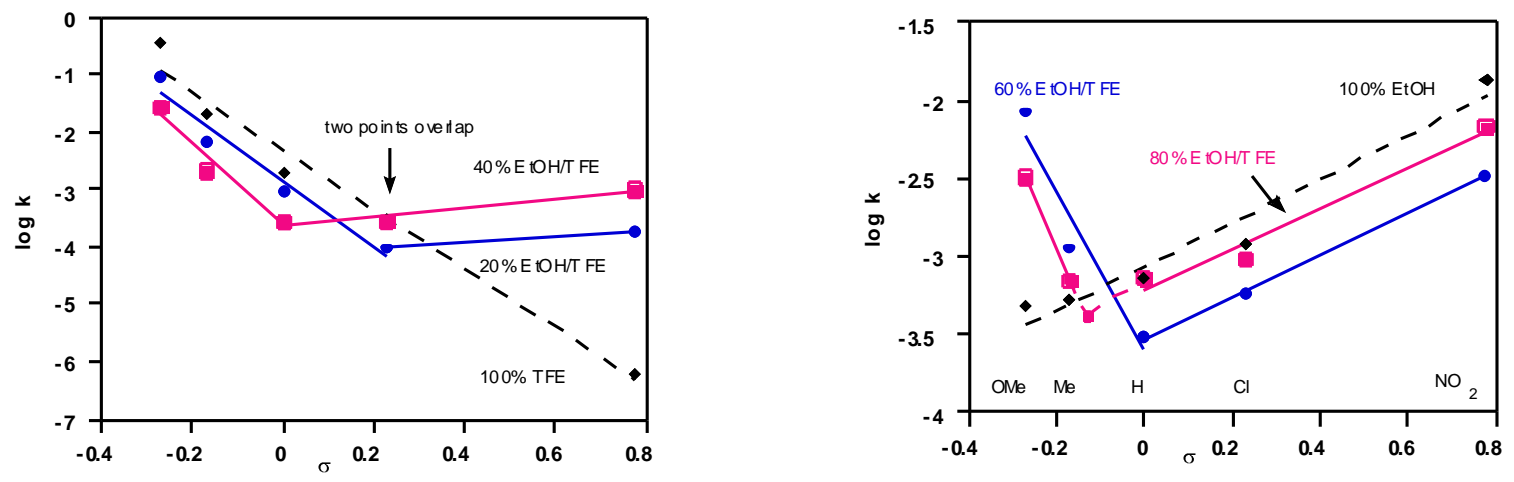

Figure 4. Logarithms of rate constants for solvolyses of acid chlorides (1) in ethanoltrifluoroethanol vs. Hammett $\sigma$; data from Table 2, but halving the rate constants for $\mathbf{1}, \mathrm{Z}=\mathrm{MeO}$ in $\mathrm{EtOH}, \mathbf{1}, \mathrm{Z}=\mathrm{H}$ in 40 and $60 \% \mathrm{EtOH} / \mathrm{TFE}$, and 1, $\mathrm{Z}=\mathrm{Cl}$ in $20 \% \mathrm{EtOH} / \mathrm{TFE}$ to correct approximately for competing reaction pathways; the correlation lines shown for $80 \% \mathrm{EtOH} / \mathrm{TFE}$ are extrapolated to calculate the position of the minimum at $\sigma=-0.13$.

The solvent effect plot for $\mathbf{1}, \mathrm{Z}=\mathrm{O}_{2} \mathrm{~N}$ (Figure 3, right) can be approximated by an initial linear region having a negative slope from ethanol to $40 \%$ ethanol/TFE (as with Figure 1, the linearity of plots is partly due to the limited range of solvents). Solvolyses of $\mathbf{1}, \mathrm{Z}=\mathrm{Cl}$ show similarly negative slopes to solvolyses of $1, Z=\mathrm{O}_{2} \mathrm{~N}$ over this solvent range (Figure 3, right), in contrast to the positive slopes for solvolyses of $\mathbf{1}, \mathrm{Z}=\mathrm{MeO}$ and $\mathrm{Me}$ (Figure 3, left); the plot for solvolyses of $\mathbf{1}, \mathrm{Z}$ $=\mathrm{Cl}$ then crosses from below to above the plot for $1, \mathrm{Z}=\mathrm{O}_{2} \mathrm{~N}$ and solvolyses in 5 and $10 \%$ ethanol/TFE show a positive slope similar to that for $\mathbf{1}, \mathrm{Z}=\mathrm{MeO}$ and $\mathrm{Me}$. Therefore, based on Figure 3, a mechanistic change for solvolyses of $1, \mathrm{Z}=\mathrm{Cl}$ occurs around $20 \%$ ethanol/TFE, consistent with the minimum at $\sigma=0.2$ for $20 \%$ ethanol/TFE (Figure 4 , left).

The solvent effect plot for $\mathbf{1}, \mathrm{Z}=\mathrm{H}$ (Figure 3, left) shows two clear linear regions, with a shallow minimum around $\log k=-1.5$ on the $\mathrm{x}$-axis, corresponding to $40 \%$ ethanol/TFE; substituent effects in $40 \%$ ethanol/TFE (Figure 4, left) show a minimum around $\sigma=0$, also consistent with a mechanistic change for $\mathbf{1}, \mathrm{Z}=\mathrm{H}$ in $40 \%$ ethanol/TFE.

These results (Figures 3 and 4) provide much clearer evidence for competing reaction channels (based on changes in slopes) than previous investigations using binary aqueous mixtures; ${ }^{7,24}$ these also include Hammett plots for ten substrates in $60 \%$ acetone/water, which show a clear minimum at $\sigma=0,{ }^{24 \mathrm{~b}}$ in agreement with the independent prediction that the mechanistic change for benzoyl chloride occurs in $60 \%$ acetone (point $\mathrm{C}$ in Figure 5 of ref. 7). Also, selectivity data in aqueous alcohols show changes in product (as well as rate) determining steps. ${ }^{6}$

Although solvolyses of benzoyl chloride $(1, Z=H)$ in water show cationic character, there is no evidence for a cationic intermediate $\left(S_{N} 1\right.$ reaction $),{ }^{10 b}$ but there is evidence from solvent effects for $\mathrm{S}_{\mathrm{N}} 2$ character. ${ }^{3 b, 25}$ We consider that there is only one reaction channel within a mechanistic $\mathrm{S}_{\mathrm{N}} 2-$ $\mathrm{S}_{\mathrm{N}} 1$ spectrum, and the competing reaction channel is a carbonyl addition process. ${ }^{10 \mathrm{~b}, 25}$ Concurrent 
stepwise and concerted substitution reactions have been proposed in other cases (e.g. reaction of 4methoxybenzyl chloride with azide ion in aqueous acetone ${ }^{26}$ ).

\section{Conclusions}

Relative rates $k(1, \mathrm{Z}=\mathrm{MeO}) / k\left(\mathbf{1}, \mathrm{Z}=\mathrm{O}_{2} \mathrm{~N}\right)$ vary from $<0.1$ in EtOH to $>10^{5}$ in TFE. Solvolyses of $\mathbf{1}, \mathrm{Z}=\mathrm{MeO}$ provide a similarity model for cationic (dissociative) reaction pathways within the $\mathrm{S}_{\mathrm{N}} 2$ $\mathrm{S}_{\mathrm{N}} 1$ mechanistic spectrum; this pathway includes relatively nucleophilic weak solvation of the developing positive charge and is favoured by electron-donating substituents and more polar solvents. Solvolyses of $\mathbf{1}, \mathrm{Z}=\mathrm{O}_{2} \mathrm{~N}$ proceed via addition (associative) pathway, except possibly in $100 \%$ TFE; the associative pathway is favoured by electron-withdrawing substituents and by solvents of low polarity, and may involve varying extents of general base catalysis by a second solvent molecule (the $\mathrm{S}_{\mathrm{N}} 3-\mathrm{S}_{\mathrm{N}} 2$ mechanistic spectrum ${ }^{27}$ ).

Rate constants for solvolyses of all 5 substrates $\left(1, \mathrm{Z}=\mathrm{MeO}, \mathrm{Me}, \mathrm{H}, \mathrm{Cl}\right.$ and $\left.\mathrm{O}_{2} \mathrm{~N}\right)$ give linear $\sigma$-plots for $100 \%$ TFE (Figure 4, left) and 100\% EtOH (Figure 4, right), but plots have opposite slopes due to a mechanistic change from dissociative to associative pathways. The slopes of two limbs of V-shaped plots for ethanol-TFE mixtures are approximately the same as either the TFE plot (Figure 4, left) or the ethanol plot (Figure 4, right), consistent with dual reaction pathways. The mechanistic change occurs when associative and dissociative pathways co-exist, and each pathway contributes $50 \%$ to observed rate constants. ${ }^{6,7,10,24}$ A decrease in electron donation (or an increase in electron withdrawal) by the substituent (Z) shifts the mechanistic change to solvents having a greater $\%$ TFE (less nucleophilic and more polar), e.g. predicted solvent compositions for each substrate are: $\mathbf{1}, \mathrm{Z}=\mathrm{MeO},(100 \% \mathrm{EtOH}), \mathbf{1}, \mathrm{Z}=\mathrm{Me}(60-80 \%$ ethanol/TFE), $1, \mathrm{Z}=\mathrm{H}(40 \%$ ethanol/TFE), $\mathbf{1}, \mathrm{Z}=\mathrm{Cl}$ (20\% ethanol/TFE), $\mathbf{1}, \mathrm{Z}=\mathrm{O}_{2} \mathrm{~N}$ (100\% TFE).

\section{Experimental Section}

General. The acid chlorides $\left(1, \mathrm{Z}=\mathrm{MeO}, \mathrm{Me}, \mathrm{H}, \mathrm{Cl}, \mathrm{O}_{2} \mathrm{~N}\right)$, were commercial samples (Aldrich), checked for purity by HPLC analysis of methanolysis products, and shown to contain $<0.3 \%$ acid; ${ }^{8}$ corresponding acids (3) were also commercial samples (Aldrich); trifluoroethyl esters (4) are previously characterized compounds, ${ }^{28}$ and were prepared by standard methods. Our sample of $\mathbf{4}, \mathbf{Z}$ $=\mathrm{O}_{2} \mathrm{~N}$ was purified by recrystallisation from $\mathrm{CCl}_{4} / 60-80$ petroleum ether (m.p. $48-50{ }^{\circ} \mathrm{C}$; lit: ${ }^{28 \mathrm{~b}} 48$ $50{ }^{\circ} \mathrm{C}$ ), and $4, \mathrm{Z}=\mathrm{Cl}, \mathrm{H}, \mathrm{Me}$ and $\mathrm{MeO}$ were purified by reduced pressure distillation; purities were established by HPLC, and all gave satisfactory combustion analyses for carbon and hydrogen. Preparations of solvolysis media, kinetic methods, and chromatographic methods were as described earlier. $^{22,27}$ 


\section{Acknowledgements}

We are grateful to the Korean Science and Engineering Foundation for financial support, to $\mathrm{M}$. Shaw (BP Chemicals) for Karl Fischer analyses, to N. Abdin and A. C. Devaney for technical assistance, and to M. Charton for helpful discussions.

\section{References}

1. (a) Carroll, F. A. Perspectives on Structure and Mechanism in Organic Chemistry: Brooks/Cole, 1998; pp 377-378. (b) Song, B. D.; Jencks, W. P. J. Am. Chem. Soc. 1989, 111, 8470.

2. (a) Jencks, W. P. Acc. Chem. Res. 1980, 13, 161. (b) Cox, R. A. Int. J. Mol. Sci. 2011, 12, 8316.

3. (a) Bender, M. L.; Chen, M. C. J. Am. Chem. Soc. 1963, 85, 30. (b) Kevill, D. N.; D’Souza, M. J. J. Phys. Org. Chem. 2002, 15, 881. (c) Lee. I.; Sung, D. D.; Uhm, T. S.; Ryu, Z. H. J. Chem. Soc., Perkin Trans. 2 1989, 1697.

4. Williams, A. Free Energy Relationships in Organic and Bio-organic Chemistry: Royal Society of Chemistry, 2003; p. 60.

5. Ruff, F.; Farkas, O. J. Phys. Org. Chem. 2011, 24, 480.

6 Bentley, T. W.; Koo, I. S. J. Chem. Soc., Perkin Trans. 2, 1989, 1385.

7 Bentley, T. W.; Koo, I. S.; Norman, S, J. J. Org. Chem. 1991, 56, 1604.

8. Bentley, T. W.; Harris, H. C. Int. J. Mol. Sci. 2011, 12, 4805.

9. Liu, K. T.; Chen, H. I. J. Chem. Soc., Perkin Trans. 2, 2000, 893.

10. (a) Bentley. T. W.; Harris, H. C. J. Chem. Soc., Perkin Trans. 2, 1986, 619. (b) Bentley, T. W.; Carter, G. E.; Harris, H. C. J. Chem. Soc., Perkin Trans. 2, 1985, 983.

11. (a) Báscuas, J.; García-Río, L.; Leis, J. R. Org. Biomol. Chem. 2004, 2, 1186. (b) García-Río, L.; Hall, R. W.; Mejuto, J. C.; Rodríguez-Dafonte, P. Tetrahedron 2007, 63, 2208.

12. Lee, I.; Koo, I. S.; Sohn, S. C.; Lee, H. W. Bull Korean Chem. Soc. 1982, 3, 92

13. Bentley, T. W.; Harris, H. C.; Koo, I. S. J. Chem. Soc., Perkin Trans. 2 1988, 783.

14. Bentley, T. W.; Garley, M. S. J. Phys. Org. Chem. 2006, 19, 341.

15. Kevill, D. N.; Ismail, N. HJ.; D’Souza, M. J. J. Org. Chem. 1994, 59, 6303.

16. Kevill, D. N.; D’Souza, M. J. Curr. Org. Chem. 2010, 14, 1037.

17. Liu, K. T.; Sheu, H. C. J. Org. Chem. 1991, 56, 3021.

18. Liu, K. T.; Chang, L. W.; Yu, D. G.; Chen, P. S.; Fan, J. T. J. Phys. Org. Chem. 1997, 10, 879.

19. Taft, R. W. J. Phys. Chem. 1960, 64, 1805.

20. Charton, M. Prog. Phys. Org. Chem. 1987, 16, 287.

21. Krygowski, T. M.; Cyrański, M. K; Sung, D. D.; Stepień, B. T. J. Phys. Org. Chem. 2004, 17, 699.

22. Bentley, T. W.; Koo, I. S.; Choi, H.; Llewellyn. G. J. Phys. Org. Chem. 2008, 21, 251.

23. Kevill, D. N. Advances in Quantitative Structure-Reactivity Relationships, Charton, M., ed. Jai Press 1996, 1,81 . 
24. (a) Cocivera, M., PhD Thesis, University of California, Los Angeles 1963, 120. (b) Lankinen, M. H.; Academic Dissertation, University of Turku 1984.

25. Bentley, T. W.; G. E. Carter, G. E.; Harris, H. C. J. Chem. Soc., Chem. Commun. 1984, 387.

26. Amyes, T. L.; Richard, J. P. J. Am. Chem. Soc. 1990, 112, 9307.

27. Bentley, T. W.; Jones, R. O.; Kang, D. H.; Koo, I. S. J. Phys. Org. Chem. 2009, 22, 799.

28. (a) Leroy, G.; Mengoni, H.; Raviart, A.; Wilante, C. Bull. Soc. Chim. Belg. 1978, 87, 171. (b) Liepinsh, E. E.; Zitsmane, I. A.; Ignatovich, L. M.; Lukevits, E.; Guvanova, L. I.; Voronkov, M. G. Zh. Obsch. Khim. 1983, 53, 1789. 